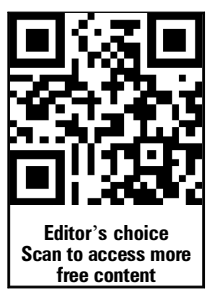

- Additional material is published online only. To view please visit the journal online (http://dx.doi.org/10.1136/ bjsports-2013-093361).

'Department of Orthopaedics, University of British Columbia, Vancouver, British Columbia, Canada

${ }^{2}$ Department of Family Practice, University of British Columbia, Vancouver, British Columbia, Canada

${ }^{3}$ Centre for Hip Health and Mobility, Vancouver Coastal Health Research Institute, Vancouver, British Columbia Canada

${ }^{4}$ Child and Family Research Institute, Vancouver, British Columbia, Canada ${ }^{5}$ School of Population and Public Health, University of British Columbia, Vancouver, British Columbia, Canada ${ }^{6}$ Population and Public Health, British Columbia Ministry of Health, Victoria, British Columbia, Canada ${ }^{7}$ School of Exercise Science, Physical \& Health Education, University of Victoria, Victoria, British Columbia, Canada

\section{Correspondence to}

Professor Heather A McKay, Centre for Hip Health and Mobility, 798-2635 Laurel Street, Vancouver, BC V5Z 1M9; heather.mckay@ubc.ca

Accepted 26 September 2014 Published Online First 13 October 2014

\title{
Action Schools! BC implementation: from efficacy to effectiveness to scale-up
}

\author{
Heather A McKay, ${ }^{1,2,3}$ Heather M Macdonald, ${ }^{1,3,4}$ Lindsay Nettlefold, ${ }^{3}$ \\ Louise C Masse, ${ }^{4,5}$ Meghan Day, ${ }^{6}$ Patti-Jean Naylor ${ }^{7}$
}

\author{
ABSTRACT \\ Objectives To describe Action Schools! BC (AS! BC) \\ from efficacy to scale-up.
}

Participants/setting Education and health system stakeholders and children in grades 4-6 from elementary schools in British Columbia, Canada.

Intervention At the provincial level, the AS! BC model reflected socioecological theory and a partnership approach to social change. Knowledge translation and exchange were embedded as a foundational element. At the school level, AS! BC is a comprehensive school health-based model providing teachers and schools with training and resources to integrate physical activity (PA) and healthy eating (HE) into the school environment. Our research team partnered with key community and government stakeholders to deliver and evaluate AS! BC over efficacy, effectiveness and implementation trials. Results On the basis of significant increases in PA, cardiovascular fitness, bone and HE in AS! BC schools during efficacy trials, the $B C$ government supported a provincial scale-up. Since its inception, the AS! BC Support Team and $>225$ trained regional trainers have delivered 4677 teacher-focused workshops (training approximately 81000 teachers), reaching approximately 500000 students. After scale-up, PA delivery was replicated but the magnitude of change appeared less. One (HE) and 4 (PA) years after scale-up, trained AS! BC teachers provided more PA and HE opportunities for students even in the context of supportive provincial policies.

Conclusions Whole school models like AS! BC can enhance children's PA and health when implemented in partnership with key stakeholders. At the school level, adequately trained and resourced teachers and supportive school policies promoted successful scale-up and sustained implementation. At the provincial level, multisectoral partnerships and embedded knowledge exchange mechanisms influenced the context for action at the provincial and school level, and were core elements of successful implementation.

Trial registration number Clinical Trials Registry NCT01412203.

\section{INTRODUCTION}

It is widely accepted that many antecedents of adult chronic diseases are evident in childhood. ${ }^{1-4}$ Specifically, multiple cardiovascular disease (CVD) risk factors were present in children as young as 8 years ${ }^{5}$ and a growing body of evidence links risk factors in childhood, such as overweight and obesity, to morbidity and mortality in adulthood. $^{7-12}$ The beneficial relationship between physical activity (PA), healthy eating (HE) patterns and a broad range of risk factors in children is now well established. ${ }^{13-16}$ Given the reports of low levels of
$\mathrm{PA}^{1718}$ and unhealthy eating patterns, ${ }^{1619}$ there is a global plea for effective and sustained intervention strategies that promote active lifestyles to enhance the health of children. ${ }^{20}$

Comprehensive school health and health promoting schools frameworks were identified as one of the 'seven best investments for physical activity'. ${ }^{21}$ Lodged within a 'socioecological' framework, these models incorporate many foundational tenets of health promotion. That is, they target changes to the environment, invest in developing multilevel partnerships, promote local autonomy in decisionmaking and accommodate variability within schools. ${ }^{22}$ However, Durlak and DuPre ${ }^{24}$ recognised that "developing effective interventions is only the first step toward improving the health and well-being of populations. Transferring effective programs into real world settings and maintaining them there is a complicated, long-term process...," a concept echoed by others. ${ }^{25}{ }^{26}$ Importantly, these researchers recognised a need for the academic community to move beyond efficacy trials to better understand whether effective interventions could be scaled up and have an impact in a real-world setting. Durlak and DuPre ${ }^{24}$ identified a number of components deemed 'essential' for sustained implementation. These critical elements crossed the following domains: (1) community context (evidence base, political support, funding and supportive policies), (2) provider characteristics (perceptions related to the need for and potential benefits of the intervention model, self-efficacy and skill proficiency) and (3) innovation characteristics (flexibility and compatibility) of the model. While we adopted many of the tenets voiced by Durlak and DuPre, ${ }^{24}$ we also incorporated Lewin's ${ }^{27}$ concept of 'action research' that was advanced by Stokols ${ }^{28} 29$ and aligns closely with current thinking around knowledge translation and exchange. ${ }^{30}$ That is, effective collaboration among researchers from across disciplines, and a participatory approach that engages community practitioners with diverse points of view, community organisations at all levels and policymakers are essential ingredients to scalable models. ${ }^{31}$ Consistent with our belief that widespread uptake (scale-up) of effective school-based interventions is critical to achieving a populationlevel impact, we also feel it is important that researchers engaged in these types of endeavours share their practice. Thus, our aim is to describe the approach to, and evolution of, Action Schools! BC (AS! BC) from efficacy through effectiveness to scale-up, to summarise previously reported findings and to present new findings-across a decade of sustained implementation. 


\section{Background}

Traditionally, most school-based interventions targeted PA within the context of physical education. ${ }^{32} 33$ However, as curricular time dedicated to physical education in schools diminished substantially, especially in recent years, ${ }^{34}$ there was a growing appetite for innovative models that encouraged PA opportunities beyond physical education. Thus, an 'active school' approach was recommended, whereby PA was promoted across a number of settings within schools. ${ }^{35-38}$ Effective PA to promote child health is closely aligned with healthy eating. Therefore, there is a move toward recommending HE approaches delivered outside of the school curriculum. ${ }^{39} 40$

\section{The AS! BC model}

In 2005, disturbing health trends in children served as a call to action in British Columbia, Canada. A confluence of pivotal events (including hosting the Vancouver-Whistler 2010 Olympic Games) spurred on several government Ministries, a multidisciplinary research team, community groups and education stakeholders to invest in an initiative that aimed to integrate PA within schools across British Columbia. The initiative, AS! BC, was and is a comprehensive school health model that embraces a socioecological framework, ${ }^{28} 29$ adopts many of the essential elements of scale-up and sustained implementation ${ }^{41}$ and reflects an interdisciplinary research, cross-sectoral school, community and provincial government (stakeholders) collaboration. AS! BC was developed in phases beginning with later elementary school (grade 4-6), followed by kindergarten-grade 3 and middle school. The goals of the AS! BC PA model were to: (1) provide a school environment where students had more opportunities to be more active more often, and (2) facilitate supportive community and provincial-level environments. ${ }^{42}$

In response to growing concerns about obesity and unhealthy eating patterns, a trained dietician and health promotion specialist were added to the AS! BC Support Team in 2007 to design and implement an HE component that complemented the AS! BC PA component (figure 1). The AS! BC Provincial Advisory Committee was expanded to include HE stakeholders, and the HE team utilised the same framework and processes to develop, implement and evaluate the HE component in grades 4-6. Briefly, the HE component also aimed to integrate HE into the fabric of elementary schools, and maintain this integration through partnerships with the family and community. The mandate of AS! BC was then extended to incorporate the HE component and to meet the goal of "providing more opportunities for more children and youth to make healthy choices more often."

\section{Evaluation of the AS! BC model}

Implementation and scale-up of the AS! BC model was embedded within a continuous process of stakeholder input and adaptation (figure 2) supported by data from a series of research trials. Specifically, stakeholders partnered to design, implement and evaluate the AS! BC model across four trials (spanning 6 years) to assess the (1) feasibility ${ }^{43}$ and efficacy of $\mathrm{PA}^{44-47}$ and $\mathrm{HE}^{48}$ components, (2) effectiveness ${ }^{49-51}$ (PA component) and (3) implementation after scale-up across British Columbia ${ }^{52}$ (PA and HE component). Partners adopted a long-term view of success and cycled through phases of knowledge and product development, knowledge and product transmission (efficacy

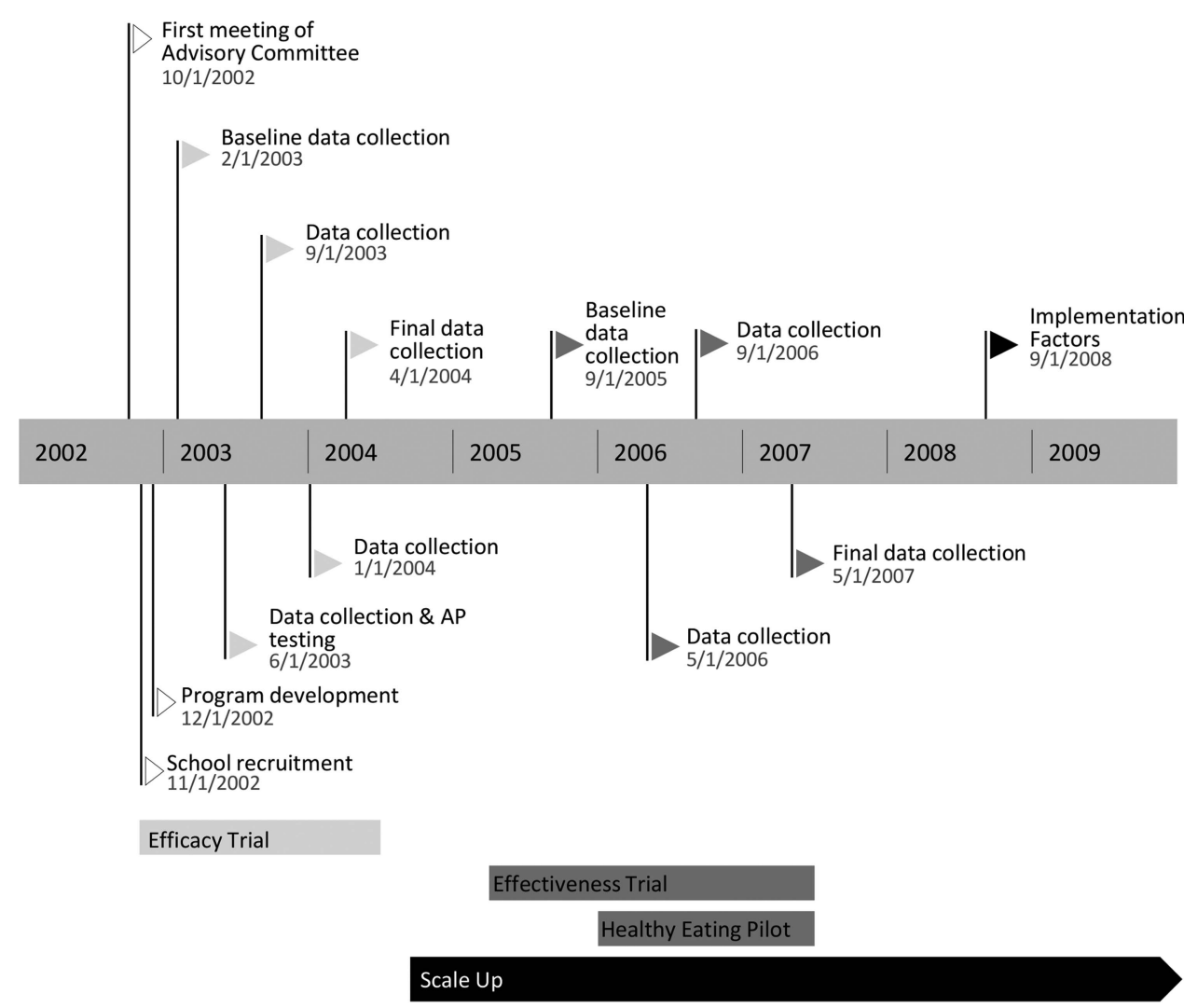

Figure 1 Action Schools! BC timeline from efficacy to scale-up. Flag colours represent various phases of the model (white-preparatory phase; light grey-physical activity efficacy trial; dark grey-effectiveness trial and healthy eating efficacy trial; black-implementation trial) and includes the start date for each activity. The model was developed in phases beginning with physical activity in older elementary schoolchildren (grade 4-6) and integrating healthy eating and younger elementary schoolchildren (kindergarten-grade 3) and middle school over time. 
Figure 2 Implementation and scale-up of the Action Schools! BC model was embedded within a continuous process of stakeholder input and adaptation supported by data from the ongoing trials.

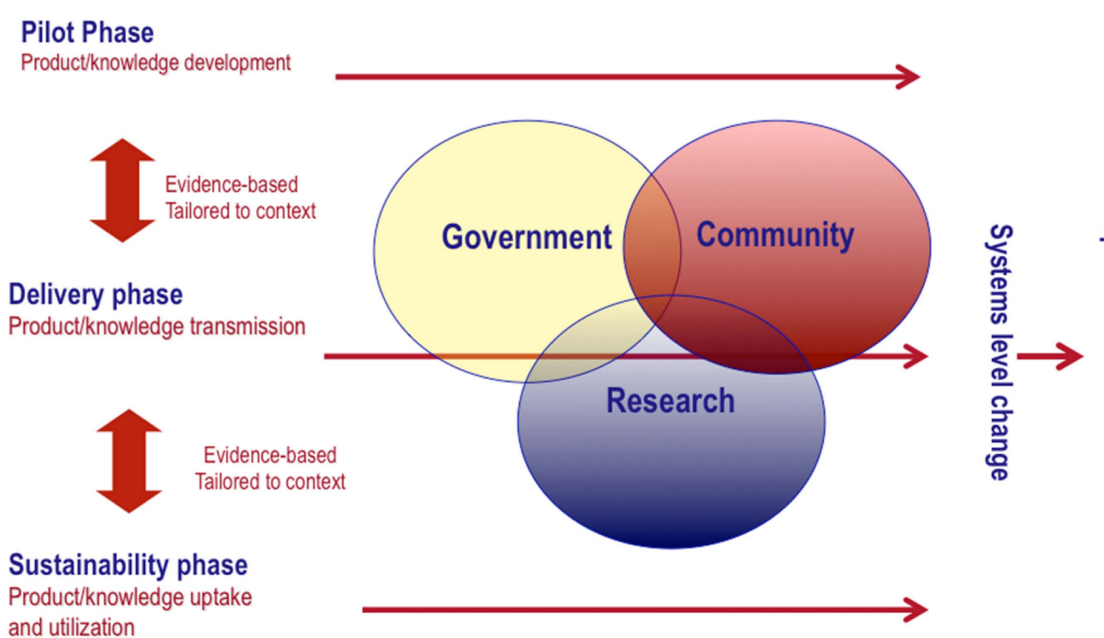

Strategic Alliances study) and knowledge and product dissemination (effectiveness and implementation studies).

Specific aims of the efficacy and effectiveness (2003-2007) trials were to assess whether: (1) teachers provided more PA and HE opportunities for students, (2) AS! BC increased PA levels of elementary (grades 4-6) students, (3) AS! BC ameliorated chronic disease risk factors and enhanced academic performance and (4) AS! BC increased the student's willingness to both try and consume more vegetables and fruit (V\&F). We also assessed the context for and facilitators and barriers to implementation of the model. Specific aims of the implementation trial (20082009) were to examine implementation of the AS! BC model and characteristics of teachers and schools and attributes of the AS! BC model ('the innovation') associated with its implementation 1 or 4 years after a province wide scale-up. ${ }^{52}$

\section{Overview of study design and participants}

The measurement timeline for the overall initiative and efficacy, effectiveness, HE efficacy and implementation trials is illustrated in figure 1. We provide a brief overview of the study design and participants of the specific trials below.

\section{PA efficacy trial (2003-2004)}

Details of the PA efficacy trial including its design, recruitment and participants have been published previously. ${ }^{43-47} \quad 53 \quad 54$ Briefly, we conducted a cluster randomised controlled trial with schools as the unit of randomisation. We recruited schools from two BC school districts (Vancouver, Richmond). Of the 20 schools that volunteered to participate, 11 met our entry criteria and 10 participated. The efficacy trial spanned 16 months (February 2003-June 2004); the AS! BC intervention was delivered over an 11-month period; children did not participate during their summer holiday (July-August).

Forty-two grade 4 and 5 teachers consented to participate from February-June 2003 (phase I) and 49 teachers participated from September 2003-June 2004 (phase II). Twenty-three teachers taught grade 4 or 5 across both years. Of 1084 eligible children, $515(48 \%)$ received parental consent to participate. Importantly, all grade 4 and 5 children enrolled in intervention schools participated in AS! BC activities, regardless of whether parents provided consent for children to be evaluated. We determined the effect of the model over either phase I and II
(18 months) ${ }^{42} 43 \quad 45-4755$ or phase II (10 months-1 school year $)^{44}{ }^{54}$-depending on the research question we addressed.

After we obtained consent, we stratified schools by size ( $<300$ or $>300$ students-to account for operational differences) and geographic location (to account for ethnic distribution). Schools were then remotely randomised to either Usual Practice (UP, $n=3$ ) or Intervention (INT, $n=7$ ). Within the INT group, there were two study arms that differed only in the amount of support offered to schools and teachers. Both groups received training in model delivery and all resources required for implementation. The 'Champion' arm $(n=3)$ had a facilitator designated from within the school while the 'Liaison' arm $(n=4)$ had an external facilitator who contacted teachers weekly. We evaluated the effect of the intervention by separate groups $^{43} 45$ or after collapsing the two intervention groups. 44464754

\section{PA effectiveness trial (2005-2007)}

As a next step, we adopted a similar process and conducted a cluster randomised controlled trial (Clinical Trials Registry NCT01412203) to evaluate the effectiveness of AS! BC after dissemination across four BC provincial health authorities over two school years. The effectiveness trial spanned 20 months (September 2005-June 2007) across two school years; children did not participate during their summer holiday (July-August). We assessed children attending 30 schools (1529 children aged 8-11 years; 64\% consent rate), randomised to the INT group ( $n=16$ schools; 747 children) or UP group ( $n=14$ schools; 782 children).

\section{HE efficacy trial (2005-2007)}

In conjunction with the PA effectiveness trial, we conducted an efficacy trial of the HE component in 10 schools $(n=300$ children at 5 INT schools; $\mathrm{n}=227$ children at 5 UP schools). The HE efficacy trial spanned 16 months (January 2006-June 2007) across two school years. As with the PA efficacy trial, we evaluated the model in two phases: March-May 2006 (phase $\mathrm{I}^{48}$ ) and September 2006-June 2007 (phase II).

Implementation after scale-up (2008-2009)

As a final step, we examined factors associated with successful implementation of AS! BC PA 4 years after scale-up ${ }^{52}$ and HE 1 year after scale-up (under review). For the PA implementation 
study, we identified 702 eligible schools and randomly invited 348 to participate. School principals $(\mathrm{n}=122 ; 92 \%$ response rate) and grade $4-7$ teachers $(n=599 ; 71 \%$ response rate) from 133 schools completed an online survey during the 2008-2009 school year. Thirty-six school principals ( $92 \%$ response rate) across 39 school districts $(\mathrm{n}=36)$ and 168 grade $4-7$ teachers (70\% response rate) agreed to participate in the HE implementation survey.

\section{Intervention-AS! BC}

The AS! BC intervention is described in detail elsewhere. ${ }^{42}$ Briefly, we adopted a multilevel, multisectoral partnership based approach that targeted two levels within the socioecological framework: (1) the meso level which represents settings or organisations that a child will interact with, and (2) the macro level which represents systems or provincial policies that influence meso-level environments. ${ }^{29}$ At the provincial level, we adopted a model that incorporated horizontal (across sectors) and vertical (from teacher to provincial policymaker) integration of stakeholders and ongoing interaction with them that supported us continuously reflecting on both their input and our data from across studies (figure 2). Later (2011), AS! BC was embedded within the Directorate of Agencies for School Health (DASH) $\mathrm{BC}$ and managed by a cross-government committee.

To achieve student-level health outcomes, we targeted the school environment using a comprehensive whole school model. ${ }^{43}$ The main components of the AS! BC model are provided in table 1. There are six Action Zones within the AS! BC model and the features of the delivery model were: a local school action team, tools to foster creation of individualised school action plans (planning and resource guides), an AS! BC central support team, a local AS! BC school facilitator and classroom action bins containing equipment and resources for providing in-class PA and promoting healthy living. ${ }^{43}$ Schools enrolled in the HE intervention arm received additional resources and training specific to the HE component. ${ }^{48}$ Schools were given an introductory workshop, assembled a team, identified their strengths and gaps across the six action zones using inventories provided by the AS! BC Support Team and set goals for action in each zone. The action bin (PA) or pack (HE) supported individualised action plans, which were reviewed and updated annually. The PA model included two prescriptive, experiential components within the Classroom Action Zone: a minimum of 15 additional minutes of PA (over and above physical education) per day $(15 \times 5)$ and jumping exercises $3 \times /$ day (Bounce at the Bell ${ }^{4756}$ ). The HE model included both curricular and experiential components within the Classroom Action Zone. HE schools were asked to provide a standard dose of two HE activities/week and one tasting activity/month within the Classroom Action Zone during phase $\mathrm{I}^{48}$ As a result of the HE phase I formative evaluation during phase II, the HE initiative emphasised three of the six Action Zones (School Environment, Classroom Action, and Family and Community) and teachers were asked to implement two Vegetable and Fruit (V \& F) Units (multiple lessons) across the fall and spring school terms (ie, two units/year, each lasting approximately 1 month), as well as monthly tasting activities and a minimum of three other activities in the school environment or family and community zone.

The growth and scale-up of the AS! BC model is planned and implemented by a provincially funded Support Team working with partners and school personnel to: (A) identify ongoing needs, (B) create and update resources based on these needs (print-based and web-based), (C) manage a phalanx of regional trainers who deliver training workshops to teachers, (D) develop and manage the AS! BC communications and marketing (including the stakeholder relations, website, newsletters, supplementary resources, reports) and (E) manage the distribution of classroom PA bins and HE packs to registered schools (1 per grade at registration). Ongoing district-level monitoring and reports are also provided to administrators and school 'Success Stories' are updated and shared through newsletters and the website (http://actionschoolsbc.ca/).

\section{METHODS}

We provide a brief description of the methods adopted to evaluate outcomes across key research objectives (these were similar between efficacy and effectiveness trials). We provide more detailed methods in our individual publications; these are summarised in online supplementary table S1.

\section{Provincial-level outcomes}

PA and HE efficacy trials

We used a descriptive case study methodology to assess the context and impact of the AS! BC model at the provincial/ systems level. We conducted three focus groups to identify the provincial-level context and impact of the project. ${ }^{42}$ The AS! BC Support Team tracked all meetings with external

Table 1 Key components of the Action Schools! BC (AS! BC) model

\begin{tabular}{|c|c|}
\hline Component & Description \\
\hline Action Zones & $\begin{array}{l}\text { Six areas in which opportunities for physical activity could be provided to students. The six zones were: (1) School Environment, } \\
\text { (2) School Spirit, (3) Physical Education, (4) Extra-curricular, (5) Family and Community and (6) Classroom Action }\end{array}$ \\
\hline AS! BC Support Team & $\begin{array}{l}\text { A central technical support unit that developed and provided AS! BC resources (training workshops, written materials, Action Bins, } \\
\text { school newsletter inserts for families) and ongoing consultation (on-site and telephone) to administrators, teachers and the School } \\
\text { Action Team }\end{array}$ \\
\hline AS! BC School Facilitators & $\begin{array}{l}\text { Two elementary schoolteachers seconded by the AS! BC Support Team to provide training, support and advice to the schools and liaise } \\
\text { between the Support Team and the School Action Team }\end{array}$ \\
\hline School Action Team & $\begin{array}{l}\text { A committee of school stakeholders (eg, interested intermediate grade teachers, administrators, parents, health, sport/recreation } \\
\text { practitioners) that created and supported implementation of the Action Plan }\end{array}$ \\
\hline $\begin{array}{l}\text { Planning Guide for Schools and } \\
\text { Teachers }\end{array}$ & $\begin{array}{l}\text { A set of inventories and worksheets that guided teachers and the School Action Team to identify school priorities and create their } \\
\text { Action Plan }\end{array}$ \\
\hline Action Pages! & $\begin{array}{l}\text { A resource directory using curriculum organisers to link teachers, coaches or community instructors with recommended and available } \\
\text { resources }\end{array}$ \\
\hline Classroom Action Bin & $\begin{array}{l}\text { A storage bin for the classroom filled with playground balls, videos, skipping ropes, exercise bands, strength grippers and teaching } \\
\text { resources that supported the Action Plan }\end{array}$ \\
\hline
\end{tabular}


stakeholders; government announcements were tracked and randomly constructed. We also used programme management information systems to describe reach.

\section{Implementation trials}

We used programme management monitoring systems to describe implementation in terms of reach, training delivered, adaptations and programme extensions.

\section{School-level outcomes}

\section{PA and HE efficacy and effectiveness trials}

Physical activity and healthy eating activities delivered: Teachers at INT schools completed weekly Activity Logs during efficacy ${ }^{43}$ and effectiveness trials. Each day teachers recorded the type, frequency and duration (minutes) of PA implemented in the classroom, in physical education or in the other Action Zones. Teachers at UP schools completed a modified version of the Activity Log. Similarly, teachers at HE schools reported HE activities. $^{48}$

Intervention fidelity and feasibility: We assessed teacher compliance with AS! BC by reviewing Action Plans and Activity Logs. ${ }^{43} 48$ As part of both efficacy trials (PA and HE), we used feedback surveys and focus groups with administrators, teachers, parents and children to evaluate intervention feasibility and determine barriers and facilitators to model delivery. ${ }^{43} 48$

$P A$ and HE implementation trials: We adopted constructs from the Theories of Organizational Change, Social Cognitive Theory and Rogers's Diffusion of Innovation Model ${ }^{57-60}$ and administered cross-sectional multistage surveys to principals and grade 4-7 teachers in 2008-2009. ${ }^{52}$ We used multilevel mixed-effect logistic regression analyses to examine characteristics of teachers and schools and attributes of the innovation associated with implementation. Specifically, we explored how 10 factors (organisational climate; organisational capacity; level of institutionalisation; environmental influences; teacher selfefficacy; outcome expectations; being physically active; teaching physical education; support for training; intervention attributes) were related to implementation of AS! BC by classroom teachers. ${ }^{52}$ As mandated provincial Daily Physical Activity (DPA) guidelines were implemented in 2008 and Guidelines for Food and Beverage Sales were enhanced, we asked about any changes in school or teacher practice related to PA and HE over the past 3 years, what influenced the change and whether they planned to use AS! BC to meet the guidelines.

\section{Student-level outcomes}

PA and HE efficacy and effectiveness trials

Descriptive characteristics of student participants: We adopted standard methods to measure each participant's standing height $(\mathrm{cm})$ and body weight $(\mathrm{kg})$ at baseline and follow-up, and we calculated body mass index (BMI) as $\mathrm{kg} / \mathrm{m}^{2}$. We used BMI values to classify children as being of normal weight, overweight or obese according to the International Obesity Task Force (IOTF) sex-specific and age-specific cut-offs. ${ }^{61}$ Ethnicity was self-reported and based on parents' and grandparents' place of birth. ${ }^{56}$ For the efficacy trial only, maturity status was assessed at baseline and follow-up using Tanner staging ${ }^{63}$ and girls' menarcheal status was determined using a self-report questionnaire.

Primary and secondary outcomes: We assessed our primary outcome, $P A$, objectively using pedometers (efficacy trial) ${ }^{45}$ or accelerometers (effectiveness trial) ${ }^{50}$ and via a self-report questionnaire (both trials). ${ }^{44-47}$
For the PA efficacy trial, we assessed cardiovascular health on a subset of children $(n=268)$ randomly selected from 8 of the 10 participating schools. ${ }^{44}$ We also evaluated blood biochemistry on a small subset of children $(n=77)$ to obtain measures of total cholesterol, high-density and low-density lipoproteins. We used peripheral quantitative $\mathrm{CT}$ to estimate tibial bone strength $^{47}$ and dual energy X-ray absorptiometry (DXA) and hip structure analysis to estimate femoral neck bone strength. ${ }^{46}$ We determined per cent body fat (\% fat) from whole body DXA scans. We assessed perceived competence with Harter's scale for children $^{64}$ and used specific subscale measures of athletic competence, social competence, academic competence and general self-esteem. $^{53} 55$ Finally, we used the Canadian Achievement Test (CAT-3) to assess the impact of AS! BC on academic performance in a subset of children $(\mathrm{n}=288) .{ }^{54}$

For the PA effectiveness trial, we measured physical fitness in a subset of 25 schools (INT: $n=640$ children; UP: $n=679$ children). For the efficacy and effectiveness trials, we evaluated cardiovascular fitness (laps completed) using Leger's $20 \mathrm{~m}$ incremental shuttle run test, ${ }^{65}$ health-related fitness using Fitnessgram $^{66}$ and blood pressure using standard methods. We also measured psychosocial variables (Physical Self-Perception Scale, Perceived Competence $\left.{ }^{64}{ }^{67}\right)$ and dietary intake $(24 \mathrm{~h}$ recall and Food Frequency Questionnaire ${ }^{68}$ ).

For the HE efficacy trial, we measured patterns of V\&F consumption via $24 \mathrm{~h}$ recalls and a Food Frequency Questionnaire in 516 children. We also assessed willingness to try and V\&F exposure using a purpose built questionnaire. We specifically focused on the: (1) number of servings of fruit/day, (2) number of servings of $\mathrm{V} \& \mathrm{~F} / \mathrm{day}$, (3) number of different $\mathrm{V} \& \mathrm{~F}$ eaten (ie, variety), (4) number of V\&F tried/eaten from a fixed list and (5) willingness to try new $\mathrm{V} \& \mathrm{~F}^{48}$

\section{RESULTS}

Results from our trials and overall programme implementation are summarised below. Results of the efficacy trial are summarised in online supplementary table S1. Baseline data for cardiovascular health, ${ }^{69-73}$ bone health ${ }^{74}$ and $\mathrm{PA}^{50}$ outcomes for AS! BC cohorts are available elsewhere.

\section{Provincial-level outcomes}

Focus group and tracking data demonstrated that AS! BC contributed to macro-level changes. ${ }^{30}$ Half of the provincial stakeholders noted that AS! BC positively affected their strategic approach and collaboration on PA initiatives. After the efficacy study was completed, the provincial government provided political support and 10 years of sustained investment (approximately $\$ 20 \mathrm{M})$ to support scale-up of the AS! BC model (integrated PA and $\mathrm{HE}$ ).

In 2006, the model was expanded from the original focus on grades 4-6 to encompass kindergarten-grade 7 . Following the efficacy trial, the Support Team developed more than 12 different specialty PA, HE and Refresher Workshops (http:// actionschoolsbc.ca/) to complement original PA and HE workshops. Over 10 years of scale-up (2004-2014), more than 225 AS! BC Trainers have been trained; 75 actively deliver training workshops to teachers each year. The Support Team and Trainers deliver 400-500 workshops per year. To date, 4677 workshops have been delivered to more than 80000 teachers. In 2006, a student leadership component was added and over 1300 student leadership workshops (outdoor games, indoor PA and $\mathrm{HE}$ ) were provided to 19000 students. AS! BC is now active in $100 \%$ of BC school districts $(n=60+)$ with $94 \%$ of 
Figure 3 Physical activity (PA; minutes/week) delivered by teachers at Usual Practice (UP), Champion (CS) and Liaison (LS) schools (efficacy trial) as well as at Intervention (INT) and UP schools (effectiveness trial). Bars represent $95 \% \mathrm{Cls}$.

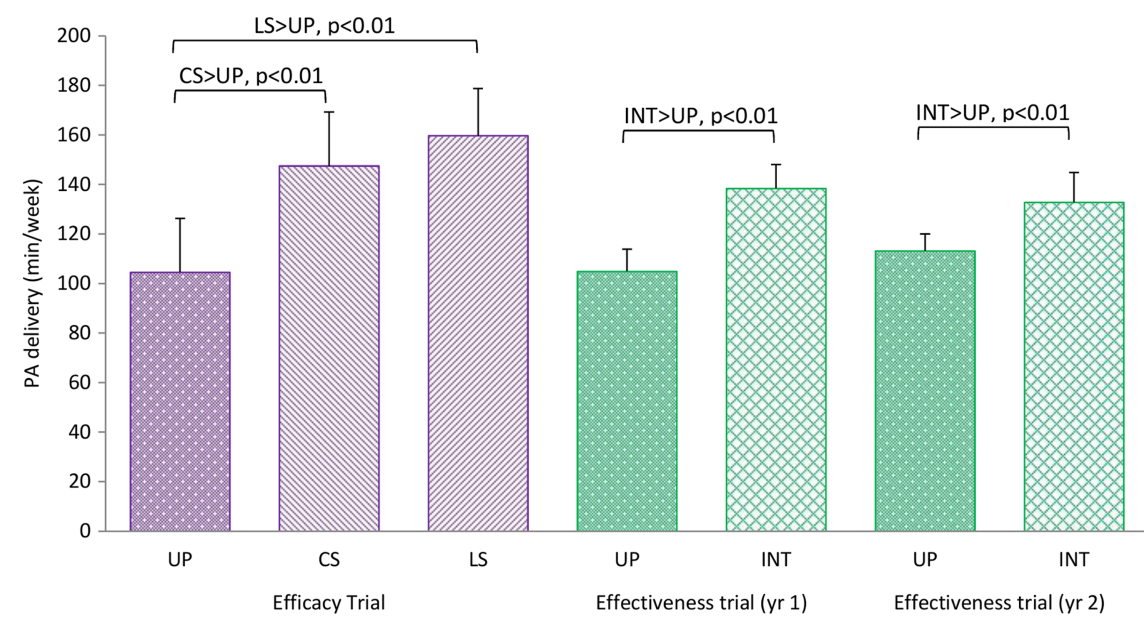

schools registered (1474/1571 schools); of those, $89 \%$ received teacher training through a workshop.

\section{School-level outcomes}

For the PA efficacy trial, PA delivered by teachers was significantly greater in both intervention arms (Liaison: $+67.4 \mathrm{~min} /$ week; 95\% CI 18.7 to 116.1 and Champion: $+55.2 \mathrm{~min} /$ week; 95\% CI 26.4 to 83.9) compared with UP schools across phases I and II (figure 3). ${ }^{42} 43$ Teacher implementation was moderate (75\% of the goal of 15 additional min/day) and Action Plans and reports showed fidelity to the AS! BC model. Teachers deemed AS! BC feasible to deliver and were highly satisfied with AS! BC training workshops, resources and facilitation by the AS! BC Support Team. ${ }^{43}$

For the HE efficacy trial, teachers reported high levels of satisfaction with the training, resources and support provided. During phase I, teachers at INT schools provided, on average, 1.3 $\pm 1.1 \mathrm{HE}$ activities per week within the classroom, and completed $80 \%$ of planned activities across five Action Zones. ${ }^{48}$ During phase II, teachers at INT schools provided, on average, 2.02 HE activities within the classroom each week and 4.1 tasting events over the school year. Generally, $76 \%$ of planned activities were completed across three targeted Action Zones.

Teacher focus groups and surveys identified time, lack of coordination between staff and lack of support from school administrators as barriers to AS! BC HE implementation in phases $\mathrm{I}^{48}$ and II. Facilitators to implementation were similar in phases $\mathrm{I}^{48}$ and II. Key facilitators were support from the Support Team, AS! BC resources, grant money (for tasting activities) and student enthusiasm.

During the effectiveness trial, teachers' compliance to completing Activity Logs was 57\% (year 1) and 66\% (year 2; range $0-100 \%)$. On average, teachers at INT schools delivered significantly more $\mathrm{PA} /$ week than teachers at UP schools in year 1 (+33.5 min/week, 95\% CI 20.6 to 46.4) and year 2 (+19.5 $\mathrm{min} /$ week, 95\% CI 5.9 to $33.1 \mathrm{~min} /$ week). PA delivery in year 1 compared with year 2 was not significantly different (-5.6 $\mathrm{min} /$ week, $95 \% \mathrm{CI}-9.5$ to $20.8 \mathrm{~min} /$ week).

During the implementation trial, and in the context of a Provincial DPA guideline being implemented (requiring $30 \mathrm{~min} /$ day of PA), an AS! BC teacher was 2.5 times $(\mathrm{p}<0.002)$ more likely to be providing greater than $15 \mathrm{~min} /$ day of classroom PA breaks for their class. A large majority of principals (96\%) and teachers $(75 \%)$ indicated that they were using or planning to use AS! BC to meet DPA requirements. School principals reported that the priority given to PA and HE had increased in the past 3 years; $76 \%$ indicated an increase in priority for PA and $86 \%$ an increase related to HE. Eighty-six per cent of these principals attributed this increase to a combination of AS! BC (voluntary model) and the implementation of DPA requirements (a non-voluntary guideline). Similarly, of the principals who reported an increased priority given to $\mathrm{HE}$ over the past 3 years, $51 \%$ attributed this to both AS! BC and the Guidelines for Food and Beverage Sales in BC Schools.

Univariate analysis identified seven factors that were significantly associated with implementation: teacher self-efficacy (eg, confidence in their skills), outcome expectation (eg, belief in the benefits), training (eg, participation in AS! BC workshops), organisational climate/support (eg, HE was a priority), level of institutionalisation (eg, supportive guidelines or policy, adapted concepts to fit their school, allocated budget), environmental influence (eg, compliance with Provincial guidelines) and attributes of the innovation (eg, relative advantage). Only training, level of institutionalisation and teacher self-efficacy remained significant in the multilevel analysis. ${ }^{52}$

\section{Student-level outcomes}

Descriptive characteristics

Our efficacy cohort reflected the demographics of Vancouver's Lower Mainland, which has the highest proportion of visible minorities in Canada. ${ }^{75}$ Most children (54\%) were of Asian descent. At baseline, $41 \%$ of children accumulated less than $60 \mathrm{~min} /$ day of PA, while $12 \%$ accumulated less than $30 \mathrm{~min} /$ day. Most children (58\%) had at least one CVD risk factor and 9\% of the sample had four or more risk factors. ${ }^{73}$ At baseline, 23\% of boys and $19 \%$ of girls were overweight and $9 \%$ of boys and $4 \%$ of girls were obese (IOTF criteria ${ }^{61}$ ). Only $37 \%$ of children consumed six or more servings/day of $\mathrm{V} \& \mathrm{~F}$ at baseline.

In contrast, children who participated in the effectiveness trial more closely reflected the demographics of the whole province of BC $\left(2006\right.$ census $\left.^{76}\right)$. Most children (56\%) were of North American/European descent, while the rest were of East, South East or South Asian (24\%), North American Aboriginal (10\%), or mixed/other (10\%) descent. At baseline, 33\% of children accumulated less than $60 \mathrm{~min} /$ day of $\mathrm{PA}$, while $13 \%$ accumulated less than $30 \mathrm{~min} /$ day. Using IOTF criteria,${ }^{61} 21 \%$ of boys and $19 \%$ of girls were overweight and $10 \%$ of boys and $6 \%$ of girls were obese at baseline.

\section{Physical activity}

PA levels in the efficacy trial, as measured by pedometer steps/ day averaged across four time points, were significantly higher 
$(\mathrm{p}=0.03)$ among boys attending AS! BC Liaison Schools compared with boys attending UP schools (+1175 steps/day, 95\% CI 97 to 2253). ${ }^{45}$ Boys attending AS! BC Champion Schools tended to have higher PA than boys attending UP schools, but this difference was not statistically significant (+804 steps/day, $95 \% \mathrm{CI}-341$ to $1949 ; \mathrm{p}=0.17$ ). Among girls, there were no between-group differences in PA as measured by a pedometer. As measured by a questionnaire (averaged across three time points), girls attending AS! BC schools had a higher average PA score compared with children attending UP schools $(2.61 \pm 0.42$ vs $2.55 \pm 0.37) .{ }^{44}$ Girls attending AS! BC Champion Schools reported significantly more minutes of daily moderate-to-vigorous physical activity (MVPA) than both AS! BC Liaison School (+19 $\mathrm{min} /$ day, $\mathrm{p}=0.005)$ and UP girls $(+14 \mathrm{~min} /$ day, $\mathrm{p}=0.04)$.

\section{Cardiovascular health}

Children in the PA efficacy trial INT group had a 20\% greater improvement in the number of laps completed compared with the UP group (+10 laps for INT compared with -1 lap for UP from baseline to follow-up after adjustment, $\mathrm{p}<0.05) .{ }^{44}$ At follow-up, and after adjusting for baseline values, the INT group completed $6.6(95 \%$ CI 3.8 to 9.5$)$ more laps than the UP group (corresponding to a difference in the estimated $\mathrm{VO}_{2}$ max of $1.6 \mathrm{~mL} / \mathrm{kg} / \mathrm{min}$ ). AS! BC children also demonstrated a significant decrease $(-6 \%)$ in systolic blood pressure compared with an increase in the UP group $(-3 \mathrm{~mm} \mathrm{Hg}$ for INT compared with $+4 \mathrm{~mm} \mathrm{Hg}$ for UP from baseline to follow-up after adjustment, $\mathrm{p}<0.05) .{ }^{44}$ AS! BC children deemed 'at risk' at baseline, based on several CVD indicators, had greater changes in fitness and blood pressure compared with their 'at-risk' peers in the UP group $(p<0.05){ }^{77}$ In the effectiveness trial, girls and boys attending AS! BC schools had a greater improvement $(+40 \%)$ in fitness compared with the UP group after the first year of intervention (under review).

\section{Bone health}

In the efficacy trial, prepubertal boys in AS! BC schools tended to have a greater increase in bone strength than UP boys at the distal $(\sim 3 \%)$ and mid tibia $(\sim 2 \%) .{ }^{47}$ At the hip, the change in bone strength tended to be greater $(\sim 2 \%)$ for AS! BC girls than UP girls (intent-to-treat analysis). ${ }^{46}$ This change was significantly greater in girls $(n=43, p=0.03)$ whose teachers reported at least $80 \%$ compliance with the intervention. AS! BC boys also had greater gains $(2-3 \%)$ in the lumbar spine and total body bone mineral content as measured by DXA.

\section{Healthy weight}

In the efficacy trial, changes in $\%$ body fat ${ }^{78}$ and $\mathrm{BMI}^{44}$ were not significantly different across groups.

\section{Perceived competence}

In the efficacy trial, perceived competencies (athletic, social and academic) decreased significantly over time in boys and girls. ${ }^{55}$

\section{Academic performance}

Children attending UP schools scored significantly higher on the CAT-3 compared with children attending AS! BC schools at baseline (June 2003). ${ }^{54}$ Despite this, test scores between children attending AS! BC and UP schools were not significantly different at follow-up (June $2004 ;-15.3 ; 95 \%$ CI -41.8 to 11.2 ).

\section{Vegetable and fruit consumption}

From baseline (Fall 2005) to follow-up (June 2007), children attending AS! BC schools demonstrated significantly greater increases in the number of servings of fruit (INT: +0.2 servings/ day vs UP: -0.5 servings/day) and V\&F (INT: +0.4 servings/ day vs UP: -0.7 servings/day) compared with children attending UP schools. They also demonstrated significantly greater increases in the variety of V\&F consumed (INT: +0.3 servings/ day vs UP: -0.2 servings/day) compared with children attending UP schools. The frequency of fruit consumption decreased at both AS! BC and UP schools, while vegetable consumption increased at both.

\section{Willingness to try new vegetables and fruit}

Children attending AS! BC and UP schools were similar in their willingness to try new V\&F at baseline. By follow-up, AS! BC children increased their willingness to try new V\&F more than children attending UP schools (INT: 3.0 vs UP: 1.1 ; a $5 \%$ greater increase in children attending AS! BC schools). Concomitantly, children attending AS! BC schools demonstrated a $10 \%$ increase in the per cent of V\&F tried compared with a $4 \%$ increase in children attending UP schools $(\mathrm{p}<0.05)$.

\section{DISCUSSION}

Scale-up and sustained investment in evidence-based school PA and HE interventions is most likely one key solution to curb downward trends in PA and HE and improve child health. We offer up AS! BC as one clear illustration of how, through committed and sustained cross-sectoral partnerships, comprehensive evaluation, feedback and adaptation, an innovative whole school model was implemented, scaled up and sustained for 10 years in British Columbia. The reach of AS! BC is substantial-94\% of schools and over 80000 teachers, administrators and other key stakeholders. We know of only a handful of other school-based models worldwide that have achieved widespread and sustained implementation, for example, CATCH $^{79}$ SPARK, ${ }^{80}$ TAKE-10!/PAAC ${ }^{81}$ and JUMP-in. ${ }^{82}$ We discuss key aspects of implementation of the AS! BC model as they relate to the literature on scale-up and implementation of other school-based PA and HE promotion.

First, we adopted a multilevel approach based on socioecological theory and established partnerships with key education, health and not-for-profit stakeholders to develop, implement and evaluate a school-level model. Second, we began efficacy trials with a potential scale-up in mind. The provincial model recognised and utilised joint decision-making with stakeholders, government partnerships and the connection between school and community at each stage and over time. We also employed an iterative approach, embedding evaluation in each stage and utilising interdisciplinary research teams and participatory processes to facilitate knowledge to action cycles. At the school level, we developed and implemented a comprehensive whole school intervention that was flexible and allowed schools to choose activities that worked best for their context while providing a required dose of PA or HE. Importantly, the AS! BC model, while including physical education and the HE curriculum, moved beyond physical education to provide more opportunities for children to make healthy choices throughout the school day. A centralised technical support unit acted, and continues to act, as a knowledge broker linking with school stakeholders to: provide training, tools and resources for them to implement PA and HE activities, develop and continue to refine tools and support resources and link the Provincial Advisory Group to school-level stakeholders and feedback.

Scaling up efficacious models into real-world settings is increasingly recognised as important in the public health research community. ${ }^{418384}$ In support of this, there is now substantial evidence across multiple disciplines regarding factors 
that support successful implementation. Damschroder et al $l^{85}$ reviewed 19 models that emerged from the implementation science literature across the healthcare, business and education sectors. Many of the factors identified in these models were common across disciplines. We adopted an implementation approach at the provincial level that incorporates factors identified as key at the macro level. ${ }^{24} 86$ Our approach also aligns with a successful scale-up model proposed by Yaney. ${ }^{84}$ Strong leadership, a local delivery system, engaged government ${ }^{87}$ and community stakeholders all played a key role in the implementation and sustainability of the AS! BC model. Importantly, we focused on identifying the needs of teachers using a cascade (train the trainer) and phased approach, tailored to context, supported by decentralised delivery and integrated into the existing education system. The school context was embedded within a supportive system-with engaged and activated school communities, substantial political will and supportive policies.

At the school level, we incorporated two conceptually distinct but inter-related components that Domitrovich et $a l^{86}$ considered key to quality school-level implementation. These were: (1) a novel intervention (AS! BC) and (2) an effective support system. This is not dissimilar to Simmons and Shiffman's ${ }^{83}$ concept of scale-up strategies.

The AS! BC model enhanced PA opportunities for students who participated. However, the measurable effects were modest. ${ }^{45}$ The most substantial health benefit from the intervention was improved cardiovascular fitness-enhanced more so in children who were considered of higher risk at baseline. ${ }^{77}$ Not surprisingly, and in keeping with effective implementation related to dose, ${ }^{24}$ beneficial effects on bone health were exaggerated in schools where the magnitude of implementation was greatest. ${ }^{46}$ Taken together, AS! BC may be an effective means to ameliorate some chronic disease risk factors in children.

Our results are similar to other school-based interventions. $^{32} 33 \quad 36 \quad 88-90$ That is, the response to our intervention varied depending on the outcome examined, the specific measure we used and the sex of participants. We found no difference for change in BMI or \% body fat across conditions. We engaged the whole school population where a large proportion (about 70\%) of children were of healthy weight. Although the converse of this, that almost $30 \%$ of children were overweight or obese, is alarming, our sample size was most likely too small and our intervention too short to positively and significantly shift this outcome. We are unable to speculate as to whether results would have been different had PA and HE components been implemented simultaneously rather than phased in over time. ${ }^{91}$ Our findings support several recent systematic reviews and meta analyses of childhood obesity prevention interventions that demonstrated improved PA levels and/or eating behaviour but no, or minimal, impact on BMI. ${ }^{92-94}$ Despite our model having no effect on body weight, it is noteworthy that cardiovascular fitness improved. This is key, given the relation of childhood fitness to obesity in adolescence ${ }^{95}$ and adulthood. ${ }^{96-98}$ Furthermore, fitness and adiposity have independent relationships with CVD risk in this age group. ${ }^{97-99}$ Studies that focused on metabolic syndrome showed that changes in diet and exercise improved insulin resistance independent of weight loss. ${ }^{100} 101$

Similar to previous longitudinal research conducted with this age group, ${ }^{102-105}$ our intervention had no impact on perceived self-competence. Although activities were chosen whereby children of all physical skill levels could participate, the model did not focus on teaching children cognitive-behavioural strategies. The intervention may have also been insufficient to overcome the age-related decline in self-concept. ${ }^{53} 102106$
Our results at the school level should be viewed in the context of the 'real world'. Schools are complex systems that adapt continuously. ${ }^{107}$ For instance, frequent changes in those who deliver the innovation (eg, teachers and administrators) are common. ${ }^{107}$ Schools most likely also respond to factors in the wider school system and community that we did not assess, for example, geographic, curricular or economic changes. Our findings, previous evidence from the implementation science literature $^{24} 25$ and the variable and dynamic nature of school contexts, frame the need for ongoing training and support for schools and teachers.

The AS! BC school model is a customised, participatory, comprehensive school health-based model that we implemented in the current context of BC elementary school education. With training and resources, schools provided at least 10 additional $\mathrm{min} /$ day of PA during the efficacy trial. ${ }^{43}$ This is comparable to physical education-based strategies (CATCH) $)^{33} 108$ and 'activity' break strategies from other jurisdictions. ${ }^{36} 90$ 109-111 However, the classroom was a key location for reaching all students and measuring change. That said, a modest increase in minutes of MVPA in physical education ${ }^{32} 108$ may have also contributed to the improved cardiovascular fitness of children in INT schools. We were unable to discern the time of day of PA using pedometers $^{112}$ and used accelerometers ${ }^{113}$ in our effectiveness trial to address this. Activities planned across zones other than physical education and Classroom Action were intermittent and we were unable to assess their specific contribution to overall PA. These types of whole school activities may signal cultural change and support by administrators for school-based healthy living initiatives. The process evaluation noted that teachers perceived enhanced support for PA promotion within INT schools. ${ }^{43}$

Ours is one of the very few studies in the literature that examined factors thought to influence scale-up and dissemination of a school-based PA and HE model. Notably, SPARK assessed sustainability 4 years after dissemination. ${ }^{80}$ Most other studies examined factors that influenced implementation in efficacy trials. ${ }^{106}{ }^{114-120}$ A takeaway message regarding scale-up is the importance of policies and guidelines (eg, provincially mandated PA or dietary guidelines; school policy to include PA in all school assemblies) that support adoption and sustained implementation $^{52} 121$ and the need to create a supportive environment for implementation, for example, by providing adequate training and resources for teachers. ${ }^{52}$

We acknowledge that our trials had several limitations and many of these have been noted in our published work. Our ability to draw conclusions about subtle changes in PA and health outcomes was limited by measurement challenges with children (especially for PA) that $\mathrm{we}^{43}$ and others ${ }^{122}{ }^{123} \mathrm{docu}-$ mented previously. Our efficacy trial was developed within some real-world 'constraints' that typically influence public health interventions and evaluations. Most importantly, we implemented the model amidst a rapidly changing social context for action on PA and HE. Our effectiveness trial was even more pragmatic in nature and measured the impact of a delivery approach that was financially feasible during scale-up where teachers received training but slightly less school level support than in the efficacy study. This may explain the lower volume of PA delivered by teachers in the effectiveness trials compared with the efficacy trial. AS! BC was also implemented in the context and aftermath of a Provincial teacher strike that may have dampened the enthusiasm of some teachers for voluntary add-ons. We acknowledge that the magnitude of some effects on children's health was small. For example, during the efficacy trial, children in the intervention group demonstrated 2-3\% greater 
gains in bone mass and strength compared with controls. We were unable to evaluate sustainability of these outcomes, or the impact these small improvements would have on adult bone health and fracture risk. However, other school-based studies demonstrated sustained benefits of a PA intervention on bone health 8 years after cessation of the intervention, ${ }^{124}$ and recent evidence suggests that participation in PA during childhood provides sustained, ${ }^{125}$ and even lifelong, ${ }^{126}$ benefits to bone strength. Furthermore, the onset of osteoporosis might be delayed by 13 years $^{127}$ and risk of fracture in postmenopausal women halved ${ }^{128}$ if the peak bone mass were increased by $10 \%$ or $1 \mathrm{SD}$, respectively. Small changes in health-related behaviour during childhood may also impact adolescent and adult health due to the tracking of behaviours across these time frames. ${ }^{129}$ Finally, it seems important that public health action on child health extend beyond the school door if we are to stem the obesity epidemic, as there is little evidence that PA within school transfers to out-of-school activity. ${ }^{32} 36108130131$ School-based approaches might best be considered as one component of a broader social change strategy.

In closing, the success of AS! BC in British Columbia to date speaks of the readiness of the community to adopt a model that addresses the health concerns confronting a generation of children and adolescents, their parents, teachers, health practitioners and the larger community. In future, sustained multisite trials that engage larger numbers of schools and children are required to account for the clustering inherent in school-based research and to determine the impact of school-based interventions on overweight and obesity. However, in jurisdictions where leveraging funding for such large longitudinal trials is a challenge, we believe that mixed methods and multiple studies over time may contribute substantially to the knowledge base. In addition, we encourage studies that compare and combine voluntary and policy-regulated models to determine if implementation levels and issues vary substantially based on approach.

\section{What are the new findings?}

- Ongoing, multidisciplinary and cross-sectoral research partnerships may enhance the potential of school-based initiatives to have public health impact.

- The development, adaptation and evaluation of school-based physical activity and healthy eating interventions from efficacy to effectiveness to provincial/state level scale-up is essential to understand whether these models can be implemented and sustained in real-world settings. This demands substantial investment by government and engaged collaborators across research disciplines, schools, communities and multiple levels and sectors of government.

- At the school level, whole school models, such as Action Schools! BC, can positively influence children's physical activity, health and healthy eating attitudes and behaviours.

- In real-world settings such as schools, effects may diminish over time. Thus, it is essential that ongoing training and supportive policies and guidelines are in place. Where training and supportive policies are in place, implementation of physical activity and healthy eating models is greater.

Acknowledgements The authors would like to express their gratitude to all of the students, parents, teachers, administrators, community and government stakeholders who participated in and contributed to AS! BC over the years. Special thanks to the AS! BC Support Team led by Bryna Kopelow and Jennifer Fenton of JW Sporta who inspired teachers to take up the call and become school champions and/or Master Trainers. They also thank the research staff and the many trainees who were integral to the success of $A S ! B C$ since its inception.We gratefully acknowledge funding support from the BC Ministry of Health, 2010 Legacies Now, the BC Ministry of Education, BC Ministry of Tourism, Sport, and the Arts, the Provincial Health Services Authority, the Heart and Stroke Foundation of Canada (BC Heart PG05-0327) and the Canadian Institutes of Health Research [CIHR (OCO 74248; PJN, PI)].

Contributors HAM and P-JN were involved in study conception and design. HMM, LN, LCM and MD were involved in data collection. HAM, HMM, LN, LCM, MD and P-JN were involved in data analysis and interpretation; drafting and revising the manuscript; final approval of the submitted version; agreement to be accountable for all aspects of the work

Competing interests None.

Ethics approval Clinical Research Ethics Board-University of British Columbia.

Provenance and peer review Not commissioned; externally peer reviewed.

\section{REFERENCES}

1 McGill HCJ, McMahan CA, Herderick EE, et al. Origin of atherosclerosis in childhood and adolescence. Am J Clin Nutr 2000;72:1307S-15S.

2 Berenson GS, Srinivasan SR, Bao W, et al. Association between multiple cardiovascular risk factors and atherosclerosis in children and young adults. The Bogalusa Heart Study. N Engl J Med 1998;338:1650-6.

3 Khan K, McKay HA, Haapasalo H, et al. Does childhood and adolescence provide a unique opportunity for exercise to strengthen the skeleton? J Sci Med Sport 2000;3:150-64.

4 MacKelvie KJ, Khan KM, McKay HA. Is there a critical period for bone response to weight-bearing exercise in children and adolescents? A systematic review. $\mathrm{Br} J$ Sports Med 2002;36:250-7; discussion 257.

5 Ribeiro JC, Guerra S, Oliveira J, et al. Physical activity and biological risk factors clustering in pediatric population. Prev Med 2004;39:596-601.

6 Andersen LB, Harro M, Sardinha LB, et al. Physical activity and clustered cardiovascular risk in children: a cross-sectional study (The European Youth Heart Study). Lancet 2006;368:299-304.

7 Mossberg HO. 40-year follow-up of overweight children. Lancet 1989;2:491-3.

8 Dietz WH. Childhood weight affects adult morbidity and mortality. J Nutr 1998:128:411S-14S

9 Gunnell DJ, Frankel SJ, Nanchahal K, et al. Childhood obesity and adult cardiovascular mortality: a 57-y follow-up study based on the Boyd Orr cohort. Am J Clin Nutr 1998;67:1111-18.

10 Baker JL, Olsen LW, Sorensen TI. Childhood body-mass index and the risk of coronary heart disease in adulthood. N Engl J Med 2007;357:2329-37.

11 Franks PW, Hanson RL, Knowler WC, et al. Childhood obesity, other cardiovascular risk factors, and premature death. N Engl J Med 2010;362:485-93.

12 Ness AR, Maynard M, Frankel S, et al. Diet in childhood and adult cardiovascular and all cause mortality: the Boyd Orr cohort. Heart 2005;91:894-8.

13 Andersen LB, Riddoch C, Kriemler $\mathrm{S}$, et al. Physical activity and cardiovascular risk factors in children. Br J Sports Med 2011;45:871-6.

14 Janssen I, Leblanc AG. Systematic review of the health benefits of physical activity and fitness in school-aged children and youth. Int J Behav Nutr Phys Act 2010;7:40.

15 Mikkila V, Rasanen L, Raitakari OT, et al. Major dietary patterns and cardiovascular risk factors from childhood to adulthood. The Cardiovascular Risk in Young Finns Study. Br J Nutr 2007;98:218-25.

16 Shields M. Overweight and obesity among children and youth. Health Rep 2006; 17:27-42.

17 Colley RC, Garriguet D, Janssen I, et al. Physical activity of Canadian children and youth: accelerometer results from the 2007 to 2009 Canadian Health Measures Survey. Health Rep 2011;22:1-9.

18 Troiano RP, Berrigan D, Dodd KW, et al. Physical activity in the United States measured by accelerometer. Med Sci Sports Exerc 2008;40:181-8.

19 Plotnikoff RC, Karunamuni N, Spence JC, et al. Chronic disease-related lifestyle risk factors in a sample of Canadian adolescents. J Adolesc Health 2009;44:606-9.

20 Weiler R, Allardyce S, Whyte GP, et al. Is the lack of physical activity strategy for children complicit mass child neglect? Br J Sports Med 2014;48:1010-13.

21 Global Advocacy for Physical Activity (GAPA) the Advocacy Council of the International Society for Physical Activity and Health (ISPAH). NCD prevention: investments that work for physical activity. Br J Sports Med 2012;46:709-12.

22 Allensworth DD, Kolbe LJ. The comprehensive school health program: exploring an expanded concept. J Sch Health 1987;57:409-12.

23 Deschesnes M, Martin C, Hill AJ. Comprehensive approaches to school health promotion: how to achieve broader implementation? Health Promot Int 2003; 18:387-96. 
24 Durlak JA, DuPre EP. Implementation matters: a review of research on the influence of implementation on program outcomes and the factors affecting implementation. Am J Community Psychol 2008;41:327-50.

25 Fixsen DL, Naoom SF, Blase KA, et al. Implementation research: a synthesis of the literature. FMHI Publication \#231, 2005.

26 Wandersman A, Duffy J, Flaspohler $\mathrm{P}$, et al. Bridging the gap between prevention research and practice: the interactive systems framework for dissemination and implementation. Am J Community Psychol 2008;41:171-81.

27 Lewin K. Field theory in social science; selected theoretical papers. New York: Harper \& Row, 1951.

28 Stokols D. Translating social ecological theory into guidelines for community health promotion. Am J Health Promot 1996;10:282-98.

29 Stokols D. Establishing and maintaining healthy environments. Toward a social ecology of health promotion. Am Psychol 1992;47:6-22.

30 Graham ID, Logan J, Harrison MB, et al. Lost in knowledge translation: time for a map? J Contin Educ Health Prof 2006;26:13-24.

31 Haggis C, Sims-Gould J, Winters M, et al. Sustained impact of community-based physical activity interventions: key elements for success. BMC Public Health 2013;13:892-2458-13-892.

32 Sallis JF, McKenzie TL, Alcaraz JE, et al. The effects of a 2-year physical education program (SPARK) on physical activity and fitness in elementary school students. Sports, Play and Active Recreation for Kids. Am J Public Health 1997;87:1328-34.

33 Luepker RV, Perry CL, McKinlay SM, et al. Outcomes of a field trial to improve children's dietary patterns and physical activity. The Child and Adolescent Trial for Cardiovascular Health. CATCH collaborative group. JAMA 1996;275:768-76.

34 Marshall J, Hardman K. The state and status of physical education in schools in international context. Eur Phys Educ Rev 2000;6:203-29.

35 Fox KR, Cooper A, McKenna J. The school and promotion of children's health-enhancing physical activity: perspectives from the United Kingdom. J Sch Health 2004;23:338-58.

36 Kriemler S, Zahner L, Schindler C, et al. Effect of school based physical activity programme (KISS) on fitness and adiposity in primary schoolchildren: cluster randomised controlled trial. BMJ 2010;340:c785.

37 De Meij JS, Chinapaw MJ, Kremers SP, et al. Promoting physical activity in children: the stepwise development of the primary school-based JUMP-in intervention applying the RE-AIM evaluation framework. Br J Sports Med 2010:44:879-87.

38 Naylor PJ, McKay HA. Prevention in the first place: schools a setting for action on physical inactivity. Br J Sports Med 2009;43:10-13.

39 Perry $\mathrm{CL}$, Bishop DB, Taylor GL, et al. A randomized school trial of environmental strategies to encourage fruit and vegetable consumption among children. Health Educ Behav 2004;31:65-76.

40 Perry CL, Bishop DB, Taylor G, et al. Changing fruit and vegetable consumption among children: the 5-a-Day Power Plus program in St. Paul, Minnesota. Am J Public Health 1998;88:603-9.

41 Milat AJ, King L, Bauman AE, et al. The concept of scalability: increasing the scale and potential adoption of health promotion interventions into policy and practice. Health Promot Int 2013;28:285-98.

42 Naylor PJ, Macdonald HM, Reed KE, et al. Action Schools! BC: a socioecological approach to modifying chronic disease risk factors in elementary school children. Prev Chronic Dis [serial online] 2006;3:A60.

43 Naylor PJ, Macdonald HM, Zebedee JA, et al. Lessons learned from Action Schools! BC - an 'active school' model to promote physical activity in elementary schools. J Sci Med Sport 2006;9:413-23.

44 Reed KE, Warburton DE, Macdonald HM, et al. Action Schools! BC: a school-based physical activity intervention designed to decrease cardiovascular disease risk factors in children. Prev Med 2008:46:525-31.

45 Naylor PJ, Macdonald HM, Warburton DE, et al. An active school model to promote physical activity in elementary schools: Action Schools! BC. Br J Sports Med 2008;42:338-43.

46 Macdonald HM, Kontulainen SA, Petit MA, et al. Does a novel school-based physical activity model benefit femoral neck bone strength in pre- and early pubertal children? Osteoporos Int 2008;19:1445-56.

47 Macdonald HM, Kontulainen SA, Khan KM, et al. Is a school-based physical activity intervention effective for increasing tibial bone strength in boys and girls? J Bone Miner Res 2007;22:434-46.

48 Day ME, Strange KS, McKay HA, et al. Action schools! BC-healthy eating: effects of a whole-school model to modifying eating behaviours of elementary school children. Can J Public Health 2008;99:328-31.

49 Nettlefold L, McKay HA, McGuire KA, et al. Action Schools! BC: a whole-school physical activity model to increase children's physical activity. I Sci Med Sport 2013;15:S114.

50 Nettlefold L, McKay HA, Warburton DE, et al. The challenge of low physical activity during the school day: at recess, lunch and in physical education. $\mathrm{Br} J$ Sports Med 2010;45:813-19.

51 Nettlefold L, McKay HA, Naylor PJ, et al. Dissemination of Action Schools! BC: effect on cardiovascular fitness over 2 years. Med Sci Sports Exerc 2012;44:239.
52 Masse LC, McKay H, Valente M, et al. Physical activity implementation in schools: a 4-year follow-up. Am J Prev Med 2012;43:369-77.

53 Rhodes RE, Macdonald HM, McKay HA. Predicting physical activity intention and behaviour among children in a longitudinal sample. Soc Sci Med 2006;62:3146-56

54 Ahamed Y, Macdonald H, Reed K, et al. School-based physical activity does not compromise children's academic performance. Med Sci Sports Exerc 2007:39:371-6

55 Rhodes RE, McKay HA. Self-esteem and competency outcomes among 4th to 6th grade students across 15 months of a school-based physical activity program. Ann Behav Med 2005;29:S067.

56 McKay HA, MacLean L, Petit M, et al. "Bounce at the Bell": a novel program of short bouts of exercise improves proximal femur bone mass in early pubertal children. Br J Sports Med 2005;39:521-6.

57 Rogers EM. Diffusion of innovations. 5th edn. New York: Free Press, 2003.

58 Bandura A. Social cognitive theory: an agentic perspective. Annu Rev Psychol 2001;52:1-26

59 Bandura A. Social foundations of thought and action: a social cognitive theory. Englewood Cliffs, NJ: Prentice Hall, 1986.

60 Steckler A, Goodman RM, Kegler MC. Mobilizing organizations for health enhancement: theories of organizational change. In: Glanz K, Lewis FM, Rimer BK, eds. Health behavior and health education: theory, research, and practice. 3rd edn. San Francisco, CA: Jossey-Bass, 2002:335-60.

61 Cole TJ, Bellizzi MC, Flegal KM, et al. Establishing a standard definition for child overweight and obesity worldwide: international survey. BMJ 2000;320:1240-3.

62 MacKelvie KJ, Khan KM, Petit MA, et al. A school-based exercise intervention elicits substantial bone health benefits: a 2-year randomized controlled trial in girls. Pediatrics 2003;112:e447-52.

63 Tanner JM. Foetus into man. Cambridge: Harvard Press, 1978.

64 Harter S. The perceived competence scale for children. Child Dev 1982;53:87-97.

65 Leger LA, Mercier D, Gadoury C, et al. The multistage 20 metre shuttle run test for aerobic fitness. J Sport Sci 1988;6:93-101.

66 Meredith MD, Welk G. Fitnessgram: test administration manual. Human Kinetics Publishers, 2004

67 Fox KR, Corbin CB. The physical self-perception profile: development and preliminary validation. J Sport Exerc Psychol 1989;11:408-430.

68 Barr SI. Associations of social and demographic variables with calcium intakes of high school students. J Am Diet Assoc 1994;94:260-6. 269; quiz 267-8.

69 Reed KE, Warburton DER, Whitney CL, et al. Secular changes in shuttle-run performance: a 23-year retrospective comparison of 9- to 11-year old children. Pediatr Exerc Sci 2006:18:364-73.

70 Reed $K E$, Warburton $D E$, Whitney $C L$, et al. Differences in heart rate variability between Asian and Caucasian children living in the same Canadian community. Appl Physiol Nutr Metab 2006;31:277-82.

71 Reed KE, Warburton DE, Lewanczuk RZ, et al. Arterial compliance in young children: the role of aerobic fitness. Eur J Cardiovasc Prev Rehabil 2005;12:492-7.

72 Nettlefold L, McKay HA, Naylor PJ, et al. The relationship between objectively measured physical activity, sedentary time, and vascular health in children. Am J Hypertens 2012;25:914-19.

73 Reed KE, Warburton DER, McKay HA. Determining cardiovascular disease risk in elementary school children: developing a healthy heart score. J Sports Sci Med 2007:6:142-8.

74 Macdonald $\mathrm{H}$, Kontulainen S, Petit $\mathrm{M}$, et al. Bone strength and its determinants in pre- and early pubertal boys and girls. Bone 2006;39:598-608.

75 Statistics Canada. Canada's ethnocultural portrait: the changing mosaic 2003;96F0030XIE2001008.

76 Ip F. 2006 Census Fast Facts: Ethnicity and Visible Minority Characteristics of BC's Population. 2008;2006-12.

77 Reed KE. Effects of a school-based physical activity model on cardiovascular disease risk factors in children: Action Schools! BC. Dissertation, University of British Columbia, 2006.

78 Kravetsky L. Targeting childhood obesity through a school-based physical activity intervention: Action Schools! BC. Dissertation, University of British Columbia, 2006.

79 Osganian SK, Parcel GS, Stone EJ. Institutionalization of a school health promotion program: background and rationale of the CATCH-ON study. Health Educ Behav 2003;30:410-17.

80 Dowda M, James F, Sallis JF, et al. Evaluating the sustainability of SPARK physical education: a case study of translating research into practice. Res $Q$ Exerc Sport 2005:76:11-19.

81 Kibbe DL, Hackett J, Hurley $M$, et al. Ten years of TAKE 10!((R)): integrating physical activity with academic concepts in elementary school classrooms. Prev Med 2011;52(Suppl 1):S43-50.

82 De Meij JS, van der Wal MF, van Mechelen W, et al. A mixed methods process evaluation of the implementation of JUMP-in, a multilevel school-based intervention aimed at physical activity promotion. Health Promot Pract 2013:14:777-90. 
83 Simmons $R$, Shiffman J. Scaling up health service innovations: a framework for action. In: Simmons R, Fajans P, Ghiron L, eds. Scaling up health service delivery: from pilot innovations to policies and programmes. World Health Organization, 2007:1-30.

84 Yamey G. Scaling up global health interventions: a proposed framework for success. PLoS Med 2011;8:e1001049.

85 Damschroder LJ, Aron DC, Keith RE, et al. Fostering implementation of health services research findings into practice: a consolidated framework for advancing implementation science. Implement Sci 2009;4:50-5908-4-50.

86 Domitrovich CE, Bradshaw CP, Poduska JM, et al. Maximizing the implementation quality of evidence-based preventive interventions in schools: a conceptual framework. Adv School Ment Health Promot 2008;1:6-28.

87 McKay HA, Macdonald $\mathrm{H}$, Reed KE, et al. Exercise interventions for health: time to focus on dimensions, delivery, and dollars. Br J Sports Med 2003;37:98-9.

88 McKenzie TL, Sallis JF, Prochaska JJ, et al. Evaluation of a two-year middle-school physical education intervention: M-SPAN. Med Sci Sports Exerc 2004;36:1382-8.

89 Gortmaker SL, Peterson K, Wiecha J, et al. Reducing obesity via a school-based interdisciplinary intervention among youth: planet health. Arch Pediatr Adolesc Med 1999:153:409-18.

90 De Meij JSB, Chinapaw MJM, van Stralen MM, et al. Effectiveness of JUMP-in, a Dutch primary school-based community intervention aimed at the promotion of physical activity. Br J Sports Med 2011;45:1052-7.

91 House J. Effectiveness of the 5-today program at increasing fruit and vegetable consumption in grade five and six children. Dissertation, University of British Columbia, 2005.

92 Harris KC, Kuramoto LK, Schulzer M, et al. Effect of school-based physical activity interventions on body mass index in children: a meta-analysis. CMAJ 2009;180:719-26.

93 Gonzalez-Suarez C, Worley A, Grimmer-Somers K, et al. School-based interventions on childhood obesity: a meta-analysis. Am J Prev Med 2009;37:418-27.

94 Waters E, de Silva-Sanigorski A, Hall BJ, et al. Interventions for preventing obesity in children. Cochrane Database Syst Rev 2011;12:CD001871.

95 Martins C, Santos R, Gaya A, et al. Cardiorespiratory fitness predicts later body mass index, but not other cardiovascular risk factors from childhood to adolescence. Am J Hum Biol 2009;21:121-3.

96 Kvaavik E, Klepp KI, Tell GS, et al. Physical fitness and physical activity at age 13 years as predictors of cardiovascular disease risk factors at ages 15, 25, 33, and 40 years: extended follow-up of the Oslo Youth Study. Pediatrics 2009;123:e80-6.

97 Eisenmann JC, Katzmarzyk PT, Perusse L, et al. Aerobic fitness, body mass index, and CVD risk factors among adolescents: the Quebec family study. Int J Obes (Lond) 2005;29:1077-83.

98 Eisenmann JC, Wickel EE, Welk GJ, et al. Relationship between adolescent fitness and fatness and cardiovascular disease risk factors in adulthood: the Aerobics Center Longitudinal Study (ACLS). Am Heart J 2005;149:46-53.

99 Andersen LB, Sardinha LB, Froberg K, et al. Fitness, fatness and clustering of cardiovascular risk factors in children from Denmark, Estonia and Portugal: the European Youth Heart Study. Int J Pediatr Obes 2008;3(Suppl 1):58-66.

100 Reinehr T, de Sousa G, Andler W. Longitudinal analyses among overweight, insulin resistance, and cardiovascular risk factors in children. Obes Res 2005;13:1824-33.

101 Nassis GP, Papantakou K, Skenderi K, et al. Aerobic exercise training improves insulin sensitivity without changes in body weight, body fat, adiponectin, and inflammatory markers in overweight and obese girls. Metabolism 2005;54:1472-9.

102 Tuckman BW, Hinkle JS. An experimental study of the physical and psychological effects of aerobic exercise on schoolchildren. Health Psychol 1986;5:197-207.

103 Marcus AC, Wheeler RC, Cullen JW, et al. Quasi-experimental evaluation of the Los Angeles Know Your Body program: knowledge, beliefs, and self-reported behaviors. Prev Med 1987; 16:803-15.

104 Bush PJ, Zuckerman AE, Theiss PK, et al. Cardiovascular risk factor prevention in black schoolchildren: two-year results of the "Know Your Body" program. Am J Epidemiol 1989:129:466-82.

105 Walters ST, Martin JE. Does aerobic exercise really enhance self esteem in children? A prospective evaluation in 3rd-5th graders. J Sport Behav 2000;23:51-60.

106 Edmundson E, Parcel GS, Feldman HA, et al. The effects of the Child and Adolescent Trial for Cardiovascular Health upon psychosocial determinants of diet and physical activity behavior. Prev Med 1996;25:442-54.
107 Keshavarz N, Nutbeam D, Rowling L, et al. Schools as social complex adaptive systems: a new way to understand the challenges of introducing the health promoting schools concept. Soc Sci Med 2010;70:1467-74.

108 McKenzie TL, Nader PR, Strikmiller PK, et al. School physical education: effect of the Child and Adolescent Trial for Cardiovascular Health. Prev Med 1996:25:423-31.

109 Vandongen $\mathrm{R}$, Jenner DA, Thompson C, et al. A controlled evaluation of a fitness and nutrition intervention program on cardiovascular health in 10- to 12-year-old children. Prev Med 1995;24:9-22.

110 Pangrazi RP, Beighle A, Vehige T, et al. Impact of Promoting Lifestyle Activity for Youth (PLAY) on children's physical activity. J Sch Health 2003;73:317-21.

111 Donnelly JE, Greene JL, Gibson CA, et al. Physical Activity Across the Curriculum (PAAC): a randomized controlled trial to promote physical activity and diminish overweight and obesity in elementary school children. Prev Med 2009;49:336-41.

112 Corder K, Ekelund U, Steele RM, et al. Assessment of physical activity in youth. J Appl Physiol 2008;105:977-87.

113 Trost SG, Tudor-Locke C. Advances in the science of objective physical activity monitoring: 3rd International Conference on Ambulatory Monitoring of Physical Activity and Movement. Br J Sports Med 2014;48:1009-10.

114 Saunders RP, Ward D, Felton GM, et al. Examining the link between program implementation and behavior outcomes in the lifestyle education for activity program (LEAP). Eval Program Plann 2006;29:352-64.

115 Wiecha JL, El Ayadi AM, Fuemmeler BF, et al. Diffusion of an integrated health education program in an urban school system: planet health. J Pediatr Psychol 2004;29:467-74.

116 Gittelsohn J, Merkle S, Story M, et al. School climate and implementation of the Pathways study. Prev Med 2003;37:S97-106.

117 Johnson CC, Li D, Galati T, et al. Maintenance of the classroom health education curricula: results from the CATCH-ON study. Health Educ Behav 2003;30:476-88.

118 Lytle LA, Ward J, Nader PR, et al. Maintenance of a health promotion program in elementary schools: results from the CATCH-ON study key informant interviews. Health Educ Behav 2003;30:503-18.

119 Kelder SH, Mitchell PD, McKenzie TL, et al. Long-term implementation of the CATCH physical education program. Health Educ Behav 2003;30:463-75.

120 McKenzie TL, Li D, Derby CA, et al. Maintenance of effects of the CATCH physical education program: results from the CATCH-ON study. Health Educ Behav 2003;30:447-62.

121 Hoelscher DM, Kelder SH, Murray N, et al. Dissemination and adoption of the Child and Adolescent Trial for Cardiovascular Health (CATCH): a case study in Texas. J Public Health Manag Pract 2001;7:90-100.

122 Jurg ME, Kremers SP, Candel MJ, et al. A controlled trial of a school-based environmental intervention to improve physical activity in Dutch children: JUMP-in, kids in motion. Health Promot Int 2006;21:320-30.

123 Sallis JF. Self-report measures of childrens physical activity. J Sch Health 1991;61:215-20.

124 Gunter K, Baxter-Jones AD, Mirwald RL, et al. Impact exercise increases BMC during growth: an 8-year longitudinal study. J Bone Miner Res 2008;23:986-93.

125 Janz KF, Letuchy EM, Burns TL, et al. Objectively measured physical activity trajectories predict adolescent bone strength: lowa Bone Development Study. Br J Sports Med 2014;48:1032-6.

126 Warden SJ, Mantila Roosa SM, Kersh ME, et al. Physical activity when young provides lifelong benefits to cortical bone size and strength in men. Proc Natl Acad Sci USA 2014;111:5337-42.

127 Hernandez CJ, Beaupre GS, Carter DR. A theoretical analysis of the relative influences of peak BMD, age-related bone loss and menopause on the development of osteoporosis. Osteoporos Int 2003;14:843-7.

128 Marshall $\mathrm{D}$, Johnell $\mathrm{O}$, Wedel $\mathrm{H}$. Meta-analysis of how well measures of bone mineral density predict occurrence of osteoporotic fractures. BMJ 1996;312:1254-9.

129 Francis SL, Morrissey JL, Letuchy EM, et al. Ten-year objective physical activity tracking: lowa Bone Development Study. Med Sci Sports Exerc 2013;45:1508-14.

130 Kriemler S, Meyer U, Martin E, et al. Effect of school-based interventions on physical activity and fitness in children and adolescents: a review of reviews and systematic update. Br J Sports Med 2011;45:923-30.

131 Dobbins M, De Corby K, Robeson P, et al. School-based physical activity programs for promoting physical activity and fitness in children and adolescents aged 6-18. Cochrane Database Syst Rev 2009;1:CD007651. 